\title{
Drugs bust reveals athletes' secret steroid
}

\section{Jonathan Knight, San Francisco}

Underground chemists may be concocting performance-enhancing drugs faster than drug testers can devise ways to spot them. That is the fear of sports physicians after revelations that dozens of élite athletes have been using an undetectable anabolic steroid to build muscle.

The US Anti-Doping Agency (USADA) received an anonymous tip-off in June that athletes were taking an undetectable steroid. The informer provided a used syringe of the substance, which the agency sent to the International Olympic Committee's drugtesting lab at the University of California, Los Angeles (UCLA).

The lab identified the compound as tetrahydrogestrinone (THG) a close relative of the anabolic steroid gestrinone, which is banned by the Olympic committee. Urine samples from some 20 athletes - who have not yet been publicly identified — have since tested positive.

This case is alarming for the authorities because the compound evades the standard two-step urine test for steroids. In this test, gas chromatography isolates steroids and a few other compounds, and mass spectrometry then determines their chemical signatures. When a new illicit steroid is found, its chemical signature needs only to be added to those against which the lab results are compared.

But THG eludes the test because the gaschromatography step does not pull it out. So after determining the molecular structure of the compound in the syringe - which took more than a month - the UCLA lab had to develop a new test for it from scratch. "As far as I know this has never happened before," says laboratory head Don Catlin.

THG may be the tip of the iceberg, says

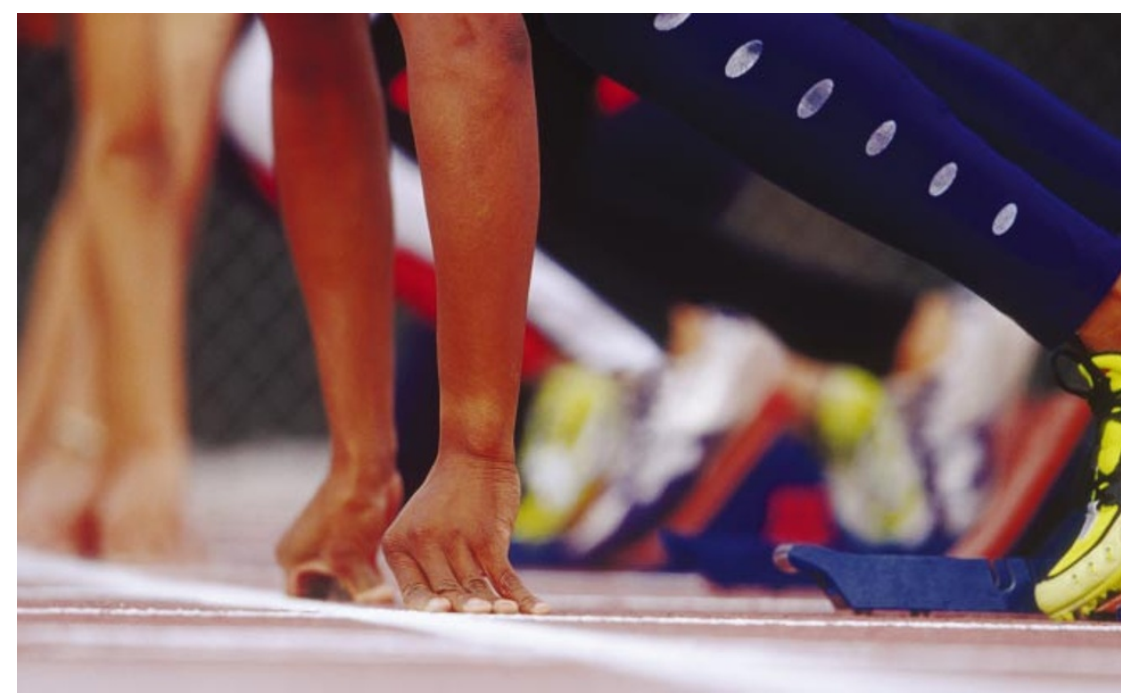

Running wild? The effectiveness of tests for banned sports drugs has been thrown into question.

Gary Wadler, a sports physician at the New York University School of Medicine and an authority on sports drugs: "It would be hard to believe that this is the only one out there."

There are strong incentives for élite athletes to use illegal performance-enhancers. When everyone is in peak condition, even a marginal benefit can mean the difference between winning and losing. And the more athletes use steroids and other enhancers, the more the incentive grows. "If they think they won't get caught, they do it," says Cynthia Kuhn, a drug-abuse researcher at Duke University in Durham, North Carolina.

Not getting caught means either quitting the supplements weeks or months before a competition at which testing is required, or using something that cannot be detected. Demand for the latter is driving a lucrative

\section{Open access wins German support}

\section{Quirin Schiermeier, Munich}

Germany's main scientific organizations have issued a joint statement backing initiatives that provide free scientific information over the Internet.

After a three-day meeting in Berlin, organizations including the Max Planck Society (MPS) and Germany's main researchfunding agency, the DFG, were due to issue the call for open access on 22 October. Openaccess backers say this is the first time that they have won formal support from all major research organizations in a large nation.

The MPS, for example, is changing scientists' employment contracts, requiring them to return the copyright of their work to the society. Researchers will still be able to publish in scientific journals, but after a grace period - the length of which is still being discussed - their papers must be deposited in at least one online repository.

The declaration evolved from a European Union-funded digital project, European Cultural Heritage Online (ECHO), which facilitates access to cultural materials (see Nature 424, 491; 2003).

Robert Schlögl, a chemist at the MPS's Fritz Haber Institute in Berlin, and coorganizer of the meeting, emphasizes that a smooth transition is necessary. "This has nothing to do with confrontation, but it has everything to do with starting a dialogue with publishing houses about a new division of labour," he says. underground market, says Wadler: "There has been a lot of bathtub chemistry going on with steroids for years."

Chemists who develop new steroids have little to fear from the law. Although banned in most sports, the compounds only fall under the US Controlled Substances Act if they are shown to build muscle, Wadler says.

Last year, Catlin's group discovered the synthetic steroid norbolethone in an athlete's urine sample. Developed by the drug firm Wyeth in 1966, it has never been marketed and has no known manufacturer today.

No one knows who first made THG. The USADA has named a Californian laboratory, Balco, as the supplier of the syringe, and has referred the matter to the Department of Justice. Balco denies distributing THG.

Drug-testing labs are left playing a hopeless game of catch-up. Tests occasionally produce signals that correspond to no known compound, says Catlin, but his lab lacks the resources to track them all. "If you decide to go after something, you are committing yourself to a lot of work," he says.

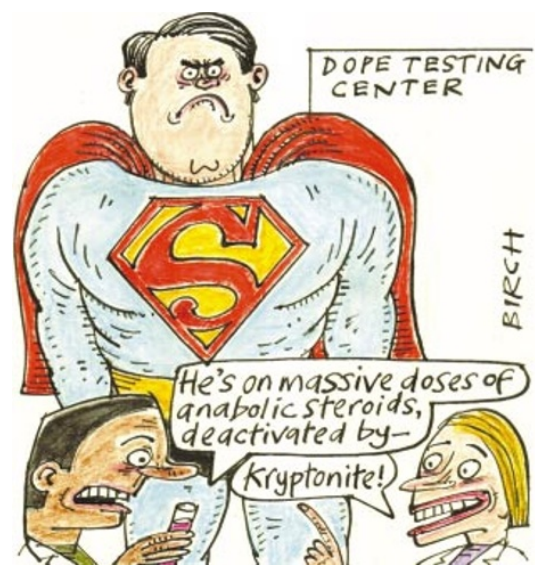

